\title{
Africanizing the South African MBA: a way of avoiding self-delusion
}

\author{
O. Harari \\ McLaren College of Business, University of San Francisco, San Francisco \\ D.T. Beaty \\ Graduate School of Business, University of Cape Town, Cape Town
}

A critical analysis of current issues facing MBA programmes in South Africa is addressed in this article. Questions of relevance of the current MBA for South African managers are explored, serious deficiencies are highlighted, and suggestions are given to redress the concerns noted by the authors. The article is concluded by anticipating and then answering possible objections to the recommendations made by the authors.

S. Afr. J. Bus. Mgmt. 1986, 17: $17-23$

In hierdie artikel word geskilpunte wat tans rondom die MBA-kursus in Suid-Afrika bestaan, krities geanaliseer. Vrae na die toepaslikheid van die MBA-kursus soos tans aangebied vir Suid-Afrikaanse bestuurders word ondersoek, belangrike leemtes word toegelig en voorstelle word gemaak om daarop te verbeter. Die artikel word afgesluit met die beantwoording van moontlike besware teen die voorstelle wat deur die outeurs gemaak is.

S.Afr. Tydskr. Bedryfsl. 1986, 17: 17-23

Paper presented at the Conference in Management and Economic Sciences, Cape Town, 29-31 October 1985

\author{
O. Harari \\ McLaren College of Business, University of San Francisco, \\ Ignatian Heights, San Francisco, CA. $94117-1080$

\section{D.T. Beaty*} \\ Graduate School of Business, University of Cape Town, Private \\ Bag, Rondebosch, 7700 Republic of South Africa \\ * To whom correspondence should be addressed
}

This article is written in order to address what we believe are some critical issues about MBA programmes in South Africa. The question that we wish to address is this: How salient, how valuable, and how relevant to South Africa is the United States model of an MBA degree? Or put in other words: How salient, valuable and relevant is the American model (or Americanizing) of the South African MBA degree to the practical needs of a South African manager?

Before addressing this key issue, we think it is necessary to define what we mean by the term 'Africanizing'. In the context of this article, we use this term for the formulation and use of a S.A. MBA curriculum which meets and embraces the needs of a South African manager. This is contrasted with the term 'Americanizing' which we define as the formulation and use of an MBA curriculum designed to meet the needs of a manager operating in the US context.

As an introduction, we want to answer a more fundamental question: What really is the purpose of an MBA? This question will be discussed from both an American and an African perspective. When using the term 'African' we are referring to those African countries most of whom espouse the political and economic systems of socialism or marxism.

From the American perspective, there are at least two schools of thought on this issue. One school of thought argues that an MBA is supposed to provide the student with a common body of knowledge in functional areas such as finance, accounting, operations, marketing, policy, human resource management, etc. The reason we use the term 'common body of knowledge' is because it is assumed that these functional skills and aptitudes are universally necessary for all managers and are generalizable across different industries, regions, cultures, and nations. Hence, the MBA is viewed as a professional degree based on a common knowledge base in key managerial functions.

From the U.S. perspective again, a second school of thought states that the value of an MBA programme should be in providing students with a set of skills and knowledge that will help them manage better in a particular situation (industry, region, culture, nation). According to this school of thought, a certain amount of uniformity across MBA programmes is both necessary and inevitable. However, this school of thought argues that applying one common standard across all business schools can be counter-productive because often skills and knowledge are not generalizable. The implication is that different MBA programmes reflect overlapping situationspecific bodies of knowledge rather than a complete common body of knowledge.

The above are two basic 'American' reasons for the value 
of an MBA. Because the American MBA has such a pervasive influence on the South African MBA (a point we will elaborate on shortly), it is obviously important to consider these two schools of thought. However, if we are to discuss the South African MBA, we must also consider the MBA process - or at least the concept of advanced management education - from another point of departure: the 'African' perspective.

In looking at the MBA or management education programmes from an African school of thought, one concludes that these programmes are very closely aligned to the overall doctrines, policies, and procedures of the African government in power. Governments in Africa require their Universities and management education programmes to be impart 'correct' ideologies (Safavi, 1985). These ideologies reflect to a large extent socialistic doctrines. This means that business and management education programmes in Africa are largely geared towards integrating the learning of political ideologies with the traditional toolbox of business knowledge and skills borrowed from traditional MBA curricula. Therefore, from the African perspective, the 'common body of knowledge' and 'situation specific' schools of thought evidenced from westerntype MBA programmes are only as salient and relevant as such knowledge is closely grounded in the external political and social ideologies of the African government in power.

Now let us consider the 'validity' of each school of thought. Is there any support for the United States 'common body' school of thought? The answer is yes. The manager's job nowadays is much more a professional position than was the case in the past. Organizations, markets, economics, information, technology, political environments, people (customers, employees, vendors) are all much more complicated and sophisticated than in the past. Therefore, a practicing manager must possess up-to-date and sophisticated functional skills in the areas of marketing, finance, and the like. Given the fact that no university programme can teach everything in the limited amount of time, and given the increasing international realization of business which calls for a common business language, it seems appropriate to base the MBA degree on a set of universally-accepted standards. In fact, this is the rationale for the highly regarded American Association of Colleges and Schools of Business (AACSB) accreditation in the United States. The AACSB sets specific uniform protocol for the curricula, students, and faculty of business schools. This accreditation is so demanding in standards that only about $20 \%$ of the Universities that offer MBA's in the United States have been able to attain it. However, the influence of the AACSB or at least the influence of its underlying assumptions about management education, is very pervasive. Thus, most MBA programmes within the USA and hence in Europe (as the United States is the acknowledged model) have a reasonably uniform curriculum.

Is there any support for the American 'situation-specific' school of thought? Again the answer is yes. A number of scholars and practitioners have suggested that the kinds of skills and knowledge that are necessary for a practicing manager in one domain may not necessarily be the kinds that are necessary in another domain. For example, observers such as Harvard University's Robert Reich (1983), Robert Hayes \& Bill Abernathy (1980), and Chrysler's Lee Iacocca (1984) have suggested that the skills necessary for effective management in one industry (say, heavy manufacturing) are often not the same as those necessary in another industry (say investment banking). In a similar vein, some of the American Universities have concluded that the knowledge base necessary for managers in the private sector is often different from that necessary in the public sector; hence, for example Harvard has a 'Business School' and a seperate 'School of Government'. Alternatively, the kinds of forecasting methods or marketing strategies effective in the United States may not be optimal in countries such as France, Indonesia or South Africa, etc. Finally, a great deal of cross-cultural and inter. national business research supports the need for differing managerial styles and philosophies depending on the nation or culture with which one is dealing.

Is there any support for the African perspective? The answer again is yes to the extent that successful managers and businessmen in African countries gencrally adhere to or at least comply with its underlying assumptions. In African countries which subscribe to socialist or marxist ideologies, the incumbent government is usually authoritarian in nature and structure (military or civilian). These governments control not only all the security forces, but also the communication channels (postal, telegraph and telephone services), the mass media (including radio, television and press), the major economic enterprises, and almost all educational institutions (Safavi, 1985). Because of government intervention in business, the management of privately held enterprises entails not only the administration of the internal environment, i.e. the production, finance, marketing and personnel functions of the firm, but also - sometimes to a greater extent - the maintaining of 'correct' relationships with government officials and agencies. The knowledge and skills of a practicing manager within these contexts is primarily orientated towards understanding and initiating business activities which reinforce the broader political, social and community goals of the state. Often these broader activities are conducted at the expense of what Westerners would call sound managerial practice. But this is not relevant in that context. Effective managers in these countries are those who can, for example, be a public relations officer, able to maintain cordial relationships with government officials and in many instances become an acting member of the ruling party and contribute heavily to a political campaign. Such government relations as those associated with obtaining import and export permits, building permits, taxation, customs tariffs, conciliatory exemptions, and obtaining business and professional licences, have often had more impact on the success of a private business than has the successful administration of internal functions. Hence, successful managers are those who can effectively mobilize and manage government relations on top of traditional management skills (these features, by the way, are characteristic of many third world countries. A recent article in the Wall Street Journal (Krause, 1985) described the hurdles and successes of a businessman in Nicaragua, using the same concepts that we describe here.) Governments in most African countries may even require managers to impart the 'correct' ideologies of the central party to their employees. Given all this, it is not surprising that Safavi (1985) concluded that management educators are required to pay special attention to subject areas beyond the business knowledge base of traditional and westernized core functional MBA curricula.

These 'schools of thought' incorporating both American and African perspectives represent diverse positions and of course are not mutually exclusive. However, we wish to use each of them as a point of departure because we believe they are both essential to the issues we wish to raise. We would like to make the suggestion that from either the American or African perspectives, there are some serious limitations with the MBA curricula in South Africa. We will begin with the first school of thought from the American perspective as a frame of reference. 
First, let's concede that the 'standard' MBA curriculum has its origins in the United States and that European and South African programmes have traditionally been modelled after the American standard. Given that, we would like to draw from the works of other critics who propose that the 'typical' US MBA curriculum - or the management philosophy that it conveys - has some serious deficiencies, and indeed, can actually be a cause of mismanagement and low productivity. Here, we refer to observers such as Peters (1983), Reich (1983), Townsend (1984), Peters \& Waterman (1982) and McCormack (1984). These criticisms can be summarized as follows: First, standard MBA programmes are entirely too sterile, too removed, and too analytically detached from the messy, grubby, irrational world of real life management. Typically, they emphasize management by abstract, often irrelevant models and management by numbers. They emphasize cost containment, cost control, and control in general. They emphasize predictability, cautiousness, and complete rationality in decision-making; even worse, they assume that the manager's world is or can be made rational, organized and predictable. They reinforce short-term thinking and success as measured by short-term (e.g. quarterly earnings, ROI) bottom line measures. They reinforce the ideas of growth via mergers, acquisitions, divestments, and creative financial 'sleight-ofhand'. Indeed, Tom Peters (1983) noted that courses in finance and accounting in the most prestigious American MBA programmes outnumber courses in sales and manufacturing (the 'guts' of business) by seven or ten to one.

What business schools do not emphasize, according to these critics, are the things that are associated with managerial effectiveness, organization vitality, and sustained growth. Hayes \& Abernathy (1980), Reich (1983) and Peters \& Austin (1985) are particularly eloquent on these points. Over and over they talk about things like obsession with customer service and quality, growth via sales of superior products and services, clean, well-maintained equipment and facilities, state-of-theart technology and hands-on knowledge, creative people management, an emphasis on revenues rather than cost, and an emphasis on constant innovation. With respect to strategy, control, and decision-making, they talk about simpler policies, fewer rules, and more vision, passion, risk, intuition and longterm perspective - not the usual staple of typical MBA programmes!

In effect, typical MBA programmes often churn out people who, while feeling self important because of their degree, are actually out of touch with the real nitty-gritty issues and problems faced by practicing managers. We tend to think that the critics are somewhat hyperbolic and extreme in their denunciations. But from our observations in our dual roles as teachers and consultants we think there is a large kernel of truth to their charges. Indeed, articles in mass media publications such as the New York Times and US News and World Report have pointed towards an increasing number of managers and academicians who are conceding the validity of some of these charges. Now remember that all these criticisms have been directed at MBA programmes in the United States. However, because the American model is the prototype for MBA programmes currently offered in South Africa, we think that these criticisms are quite generalizable. We will go a step further. We believe these issues have much more serious implications in South Africa than in the United States. We are not alone in proposing that the MBA process is as much socialization as education. Suppose, therefore, the MBA students are socialized to approach management in a detached, conservative, and analytical manner. Suppose that they are socialized to view management as an orderly and rational process that 'solves' problems via the correct numbers and models. We propose that this type of education or socialization is often counter-productive in the United States, but it becomes potentially lethal in South Africa where the salient issues faced by managers are so intense, often explosive, that they demand passion, commitment, risk, and intuition. We think that this statement is self-evident to any South African manager, and we will elaborate on this issue shortly. First, let us address some key issues from the perspective of the second United States school of thought on MBA education.

The second school of thought from an American perspective asks us to confront a parallel concern: To what extent are the kinds of skills learned in a traditional (American-based) MBA programme really generalizable across situations? Conversely, to what extent are management skills 'situation specific'? An article in the April 1985 issue of Newsweek (Henkoff, 1985) confirmed a trend we have noted when interacting with colleagues from Europe: European MBA programmes are starting to move away from the traditional American model. To quote from the article: 'Originally little more than clones of American institutions, European business schools have jettisoned most of their recycled case studies from the Harvard Business School, and evolved their own hand-on methods for studying the problems of European multi-nationals' (p.42). Europeans are modifying their MBA curricula to fit more closely with environments, organizations, issues, and problems that a practicing manager in a European firm is likely to face. However, our experiences suggest that South African Business Schools are in danger of lagging behind their European counterparts in making significant declarations about 'Africanizing' their MBA curricula. This is ironic when one compares the culture and socio-political environment of Europe (which is first world and more closely approximates that of the United States) with the culture and the socio-political environment of South Africa which is, at least currently, both of 'first world' (in power) and 'third world' (in numbers) orientation.

In looking at the South African MBA from an African 'school of thought' perspective, the issue of relevance for a South African manager is questioned further. South Africa is intimately tied to Africa geographically, politically, and economically. One can argue, in fact, that pragmatic geopolitical and commercial links are much closer among South Africa and its third-world neighbours than among South Africa and its first-world allies.

Yet, our experiences suggest that there is much in the South African MBA curriculum that is similar to an American MBA curriculum. In many instances, we believe that the South African MBA student has relatively greater exposure to business principles and practices faced by $A$ merican managers than by African ones. If this is the case, we would conclude that many South African MBA Programmes do a much better job of preparing students to manage in the US or Europe than in South Africa. When evaluated against the standards of relevance and salience for students who intend on becoming South African managers, we propose that such MBA programmes are marginal and in fact sometimes border on the delusional.

Marginality and delusion are extreme charges and we confess that we are using these terms partially for effect, but we propose that the charges have some real validity from the perspective of all three schools of thought that we have discussed. As we noted earlier, the problems of sterile MBA curricula laden with caution and 'analysis paralysis' becomes a potential catastrophe in South Africa. South Africa does 
not need myopic managers who see management as creating 'rational' plans that people and produce will supposedly fall into it neatly. That trend of thought is delusional (though ironically, it seems to be the way of thinking of many government officials). South Africa needs managers who are willing to try the extraordinary, the truly innovative, and to do so with intuition and passion as well as with the cautious and 'rational'. We say this with a growing conviction that if longterm stability and prosperity is ever to take place in South Africa, it will not be caused by government bureaucrats or ideologues who are committed to unbending out-dated beliefs and a detached mode of thinking. Instead the vanguard will be led by managers who are willing to junk the rule books and consider the extraordinary and supposedly 'impossible'.

There are a growing number of senior managers and executives willing to voice their concern and vision about the challenges that need to be faced by South African industry and commerce. We are thinking here of people like Gavin Relly of Anglo American, Tony Boom of Premier Milling, Raymond Ackerman of Pick and Pay, and other business leaders willing to take the plunge and voice their convictions about the need for corporate responsibility in facilitating political and social changes. However, the number of voices heard are very few and very far between. The kinds of risk and intensity they demonstrate need to be characteristic of daily managerial decisionmaking at all levels of management in much greater numbers and in increased volume of speech. Furthermore, South African MBA programmes need to be instilling and socializing their students with these kinds of visions and passions.

The implication from the second 'American' school of thought perspective regarding situational specificity needs closer examination. Is it a truism to state the obvious: that fundamentally South Africa and the United States (and for that matter Europe) are very different beasts? Cultures, demographics, politics, psychological, interpersonal relations, geography and history intimately affect management in South Africa and in many cases are completely different from comparable issues faced by American (or European or Japanese) managers. When American textbooks, cases, and exercises are used on South African MBA programmes, educators need to be aware that these are 'symbols' which communicate the message that management in South Africa is the same as management in the United States (or Europe). The implications communicated are that models and strategies appropriate in the United States are appropriate in South Africa. That's true only to a certain extent; the rest is both marginal and delusional. Most American texts, cases, and exercises hardly touch upon the practices vital to South African management.

We believe that South Africa does not need managers whose education is based primarily on models and strategies custom-built and tailor-made to the American (or European or Japanese) manager. South Africa needs managers who understand the unique political, cultural, and social psychological features of the country better than their non-managerial counterparts. South Africa needs managers who can use this knowledge to effect daily business decisions that will pave the way for meaningful change and reform.

The third and final 'African' school of thought perspective addresses the question of ideological relevance and the South African MBA degree. The concept of a free enterprise system is one to which most whites in South Africa subscribe. However, while most whites enjoy the fruits of the free enterprise system black workers perceive the system as solely benefiting whites and regard the system as discriminatory and unfair (Nasser, 1985). We believe that these ideological differences, which are a reality both in South Africa and in most of the countries north of its borders, need far greater and more indepth attention by MBA educators and students in South Africa. If business decisions within the 'African' context are largely influenced by political ideologies, it makes sense to debate and tackle the complexities of operating a business and generating effective management decisions within these unique political scenarios, e.g. questions relating to how does a business decision change when it is based upon a political and social system that accentuates the merits of the state at the expense of individual enterprise and initiative. These sorts of debates are critical to and should be an inherent part of all subject areas taught in South African MBA programmes, if for nothing else than to understand how decisions are made in other African countries. This sort of understanding would be critical for commercial negotiation and strategic planning.

So where do we go from here? We do have some suggestions, but first of all let us prefix our remarks by saying that many of the issues raised in this article may have been addressed by some Business Schools in South Africa. For others, we believe that the current political and social changes occurring in this country will require MBA educators to re-evaluate their standards of educating MBA students.

Our analysis of the situation and personal experiences within South Africa have convinced us that quick, decisive, and dramatically different actions are necessary in order to prevent worst-case scenarios. Moreover, we believe that business people must be in the vanguard of these actions. Secondly, we repeat unequivocally that we do not recommend the elimination of functional courses and the core business administration curriculum like marketing, finance, and the like. Nor do we propose that the present (Americanized) programme immediately and in its entirety be scrapped. Obviously, it has many redeeming features and modifying a programme does not mean throwing out the baby with the bathwater. Thirdly, we want to be realistic. Therefore we assume that the MBA paradigm in South Africa will remain based on an American model for at least the foreseeable future. Therefore, we will not venture to outline a complete model for the South African MBA degree because such a scenario requires both an in-depth and exhaustive theoretical and practical research study which is beyond the scope of this article. However, we will make some suggestions that we regard as critical first steps or as stopgap strategies to address the issues of MBA programme modification in South Africa. A few of our suggestions have already been addressed by some South African Business schools but this is the rare exception rather than the rule.

Our suggestions are therefore summarized in the following five points:

(i) Tie the present functional courses (marketing, operations, organizational behaviour, etc.) more closely to the South African context. Ideally, South African academics and researchers should write their own texts, cases and exercises. There is a growing impetus in this regard, but this movement needs to be accelerated in view of the enormous challenges faced by the South African manager of tomorrow. To the extent that American texts are used (again only as a stop-gap exercise), instructors should supplement them by developing lectures, cases, short instructional models and exercises that apply the American materials and the American readings to specific South African and African issues. This should be done regularly and we would suggest such an occurrence at every class meeting.

Of all the suggestions we will make, the above is so essential 
that it should be the bare minimum of change efforts.

(ii) Shake up the typical large-corporate, play-it-safe, manage-by-numbers MBA value system by offering guest lectures and courses in entrepreneurial value and behaviour, including risk, intuitive decision-making, the technology of 'managing by wandering around' (Peters \& Waterman, 1982), proactivity, innovation and visionary leadership. 'Nonbureaucratic' thinking and organizational designs, as well as the management of 'controlled chaos' (Quinn, 1985) would be integral parts of this curriculum (Stanford University's MBA Programme has occasionally offered courses related to Zen, vision and 'right-brain' decision-making).

(iii) Add required courses in the dynamics of cultures, psychology and history of non-whites in South Africa and Africa. Managers who work with black, coloured, Indian and English or Afrikaans employees, colleagues, or customers should have a working knowledge of their mores, norms, attitudes, perceptions, cultures, languages, etc. (We find it interesting that when Sony opened a plant in San Diego, an American city near the Mexican border, one of the first things the new plant manager (a Japanese) did was to learn Spanish. The bulk of the labourers were Mexican and Chicano). In addition to text and lecture education, invite members of these groups (make sure that all political persuasions are represented) to individually and jointly given lectures and seminars, hold discussions and focus groups with students and assign further readings and activities. Include praticals, internships, or field studies that require students to go to townships, rural areas, and organizations to talk and listen - to both whites and non-whites. Have them then report back to the class, have students talk with non-white managers, non-white workers, spouses and families about the unique problems and challenges which they face. As Tom Peters and his colleagues (In Search of Excellence; $A$ Passion for Excellence) point out repeatedly: learning by 'wandering around' is an indispensable and irreplaceable means of really understanding what's going on out there. The instructor's role is to plan, control and facilitate the above, and then to integrate this knowledge and to channel it into practical tools for the manager.

(iv) Build an additional social science segment into the programme. Have instructors in fields such as history, political science, government, psychology and communication arts give lectures and seminars on issues germane to South African managers. These lectures and discussions should revolve around South Africa the country and Africa the continent. Faculty of the business school would act as facilitators of this process and relate the material to pragmatic business concerns. The content of the curriculum would also explore ideological constraints of socialist doctrines which emphasize group and state initiatives at the expense of individual enterprise. South African MBA students need to understand the intricate connection between politics, ideology, and business in African countries (and in South Africa). Courses or segments in these areas would expose future South African managers to these key grass-root realities. The courses would also deal with how to cultivate and maintain relationships with managers in African countries, and with government agencies that have an influence on business decision-making processes. We find it interesting that European business schools, breaking away from the
American MBA mould, are supplementing standard marketing and finance courses with courses in politics and history (Henkoff, 1985). According to observers this provides valuable skills for a manager trying to do business in Europe's 'conflict-ridden societies' (Henkoff, 1985). We propose that this type of didactic strategy is even more important in South Africa than in Europe.

(v) Have all students go through a set of structured experiential exercises such as encounter groups and teambuilding sessions. The encounter groups would focus on students' racial and religious stereotypes, prejudices and fear. Team-building sessions would focus on communication barriers and inter-personal conflict among races and religious groups. Group composition would be varied: students and non-students, non-white, and white Afrikaner and English groups would be led by trained professionals. Ordinarily we are not big fans of encounter groups or other similar activities and ordinarily we would not conceive of including them as part of an MBA curriculum. However, our experiences convince us that these types of sessions can be extremely valuable - possibly essential - for South African MBA students. Race, and concomitant fears, hatreds and prejudices are woven deeply into the fabric of South African society. The South African manager is not only going to have to confront and change many of his or her attitudes, but will also have to learn how to change the attitudes of others such as employees and peers. The experiential group processes that we suggest would be an important start in this direction and specific behavioural homework assignments would assist in generalizing the gains of such a programme to practices within the worksetting.

We believe that these five suggestions, if followed, would go a long way in addressing the problems and pitfalls discussed in this article. We are sure, however, that there are some readers who are probably looking askance at these proposals. Let us anticipate some probable objections and see if we can address each one properly.

(i) Objection: Won't your suggestions lower the standard of the South African MBA?

Answer No. We assume the highest expectations and standards of excellence for the course work, field work, and experiential exercises that we have suggested. If anything, the revised MBA programme will make even greater intellectual (not to mention emotional) demands on students, and these challenges will help shape truly effective managers.

(ii) Objection: Isn't the MBA a business degree? Aren't many of your suggestions simply nonbusiness orientated?

Answer: Yes, the MBA is a business degree. As we have pointed out in this article all of the issues we have raised are intimately tied to business and management in South Africa. Not dealing with them in depth is the same as putting students through an 'Alice in Wonderland' programme which is devoid of reality.

(iii) Objection: Isn't much of the course work you advocate such as field work, social science, wandering around, and encounter groups inherently 'soft'? 
Answer: NO! Three quick points. First, class standards can be weak in any MBA course, even 'hard' ones like statistics or economics. It is the responsibility of the instructor to ensure high standards in any or all of the courses, regardless of content (see objection No. 1). Secondly, successful managers (lacocca, 1984; McCormack, 1984; Pascale \& Athos, 1981) repeatedly confirmed that the key elements in managerial success are the so-called 'soft' factors such as interpersonal skills, hunches, visions, and commitment. Thirdly, Peters and Austin (1985) summarized it best when they described managers who insist that any 'market research' have a large dose of 'soft' stuff like personally eye-balling customers, visiting them, listening to them, and empathizing with them. In describing the success of Dave Thomas, President of Wendy's Inc., they wrote

'As usual, we must go briefly on the defensive and state that we do not consider such reliance on the "eyeball" to be soft. One more time: we think the concepts of "soft" and hard have gotten badly fouled up. Most seem to believe the "eyeball" is "soft" and that computer output "hard". Both can be soft, both can be hard, but if our life depended on it and we had to cast a vote on the "hardness" of Dave Thomas' "eye" for quality versus ten pounds of MBA-and-electronic-spreadsheet-produced analysis, Thomas would get the nod, no doubt about it.' (p. 105-106).

(iv) Objection: By following your suggestions, won't the number of courses and length of time necessary to complete an MBA be increased?

Answer: Perhaps not. First, many of the changes we propose could be offered as segments of, or in lieu of, existing courses. Secondly, the options we have advocated for minimizing a 'window approach' to the South African MBA and applying instead a more relevant and 'real world' experience could be structured to take the form of on-thejob practicums. Some of these practicums could be carried out by MBA students while at work and after having completed their academic curriculum at the business school. Students would be supervised in these practicums by Business School staff and employers would gain the benefits of a transfer of knowledge and skills by the students into the work-place. This would help to streamline the problem of students spending an inordinate amount of time away from the work-place. Alternatively, such a procedure would not necessarily mean a significant increase in the length of existing MBA programmes. Thirdly, however, we should keep in mind that an emphasis on quick turnaround of MBA students is a terribly misplaced and potentially disastrous emphasis, as we have attempted to demonstrate.

(v) Objection: Won't your suggestions take away the international flavour of the South African MBA degree?

Answer: Not necessarily. Provided there is a continued maintenance of international links through the recruitment of overseas students as well as the continued use of overseas instructors on selected courses, then we believe that international links will be maintained. What we are suggesting is that the issue of a greater balance of local 'African' MBA content will not only increase the relevance of the programme in South Africa, but should also attract overseas visitors intent on examining the 'African' complexities of business practices within a country that has been frequently called a microcosm of world-wide social and political thought.

At this point we would like to make some concluding comments. We hope that our ideas have been useful and if nothing else thought-provoking. We believe that it is very important that the South African MBA be less of an American clone. We have indicated, however, that this does not mean it loses its international standing and we have not suggested doing away with rigorous courses in finance, marketing, accounting, and the like. We are merely suggesting that South African MBA educators place a greater emphasis on 'Africanizing' their MBA, which brings us to our final point. You will note that we did not say that the South African MBA should be 'South Africanized'. We said 'Africanized'. The language here (and the title of this article) is quite deliberate. Language, as Peters \& Austin (1985) pointed out repeatedly, is a vital symbol in business. Business schools and students of business in South Africa must learn to accentuate the unique 'African' flavour of their business knowledge and skills. This change in emphasis will provide the South African manager of tomorrow with not only a greater appreciation of his or her identity, but will help to perpetuate the philosophy that African business problems must be solved primarily the African way. American or European models and case solutions will not suffice to meet the unique and complex needs of the South African manager. Ideological differences influencing social, political and corporate practices combine together to make the South African manager's job perhaps more complex and difficult than that of his or her overseas counterpart. Given South Africa's shortage of both quality and quantity of managerial manpower, we believe that the needs of commerce and industry will have to be met by managers who are committed to the visions articulated in this article. South Africa needs managers who are able to say: 'I am an African' and who are able to say that their MBA education helped them understand that better, gave them specific tools for professional management in their country and gave them the spirit to believe that they can achieve the 
extraordinary in commerce and government in their land. An MBA programme that can do that is worth its weight in gold - South African gold of course.

\section{References}

Hayes, R.D. \& Abernathy, B. 1980 . Managing our way to economic decline. Harv. Bus. Rev., July-August, 67-77.

Henkoff, R. 1985. Breaking the American Mold. Newsweek (International Edition), April, 42-43.

lacocca, L. 1984. Iacocca: An Autobiography. New York: Bantam Books.

Krause, C. 1985. How one businessman manages to survive Nicaruguan Sardinistas. Wall Street J., October.

McCormack, M. 1984. What they don't teach you at Harvard Business School. New York: Bantam Books.

Nasser, M. 1985. Perceptions of free enterprise and business as an examination of the status quo in South Africa. S. Afr. J. Bus.
Mgmt. vol. 16, (1), 1-6.

Pascale, R.D. \& Athos, A. 1981. The art of Japanese Management. New York: Warner Books.

Peters, T. 1983. On political books. The Washington Monthly, October, 22-25.

Peters, T.D. \& Austin, N. 1985. A Passion for Excellence. New York: Random House.

Peters, T.D. \& Waterman, R. 1982. In Search of Excellence. New York: Harper and Row.

Quinn, J. 1985. Managing innovations: controlled chaos. Harv. Bus. Rev. May - June, 73-84.

Reich, R. 1983. The Next American Frontier. New York: Times Books.

Safavi, F. 1985. Education for World Development. Western Washington University Publication.

Townsend, R. 1970. Up the Organization. New York: Knapf.

Townsend, R. 1984. Further up the Organization. New York: Knapf. 